\title{
The Northwest Public Health Information Exchange's Accomplishments in Connecting a Health Information Exchange with Public Health
}

${ }^{1}$ Dobbs D, ${ }^{1}$ Trebatoski $M,{ }^{2}$ Revere D

${ }^{1}$ Science Applications International Corporation, McLean, VA

${ }^{2}$ Center for Public Health Informatics, University of Washington, Seattle, WA

\section{Abstract:}

In 2007 the Centers for Disease Control and Prevention (CDC) issued a Request for Proposal for the "Situational Awareness through Health Information Exchange" project. The Situational Awareness project's goals are to connect public health with health information exchanges (HIEs) to improve public health's real-time understanding of communities' population health and healthcare facility status. During this same time period the Health and Human Services' Office of the National Coordinator for Health Information Technology released several reports identifying the growing number of communities involved in health information exchange and outlining the requirements for a Nationwide Health Information Network (NHIN). CDC saw the possibilities of using HIEs and the NHIN to accelerate the real-time sharing of clinical and facility-based resource utilization information to enhance local, state, regional, and federal public health in responding to and managing potentially catastrophic infectious disease outbreaks and other public health emergencies. HIEs would provide a unified view of a patient across health care providers and would serve as data collection points for clinical and resource utilization data while NHIN services and standards would be used to capture HIE data of importance and send those data to public health. This article discusses how automated syndromic surveillance data feeds have proven more stable and representative than existing surveillance data feeds and summarizes other accomplishments of the Northwest Public Health Information Exchange in its contribution to the advancement of the National agenda for sharing interoperable health information with public health.

Keywords: Data Collection; Electronic Health Records; Health Information Exchange; Information Management; Medical Record Linkage; Public Health 


\section{Introduction}

The Situational Awareness project's goals are to connect public health with health information exchanges (HIEs) to improve public health's real-time understanding of communities' population health and healthcare facility status. During this time period (2007) Health and Human Services (HHS) Office of the National Coordinator for Health Information Technology (ONC) released several reports that identified the growing number of communities involved in health information exchange, the requirements for a Nationwide Health Information Network (NHIN) [1] and a summarization of NHIN Prototype Architectures [2] that included recommendations for a set of NHIN services and capabilities. CDC saw the possibilities of using HIEs and the NHIN to accelerate the real-time sharing of clinical and facility-based resource utilization information to enhance local, state, regional, and federal public health in responding to and managing potentially catastrophic infectious disease outbreaks and other public health emergencies. HIEs would provide a unified view of a patient across health care providers and would serve as data collection points for clinical and resource utilization data. NHIN services and standards would be used to capture HIE data of importance and send those data to public health.

Science Applications International Corporation (SAIC) conducted a thorough search process to find suitable HIEs and project stakeholders to participate in the CDC's Situational Awareness project. To get a bearing on the state of the HIE market SAIC reviewed a sample of Regional Health Information Organizations (RHIOs) in California conducted by CalRHIO in 2006, which showed that only $13 \%$ of the RHIOs were operational and actively sharing data. [3] Many RHIOs/HIEs that SAIC investigated were simply marketing and training organizations that were early in the process of evangelizing health data exchange concepts: some of the HIEs that surveys and articles labeled as "operational" had only rudimentary clinical messaging systems, and weren't capable of providing information required as part of the minimum data set; others were pilot infrastructures that had minimal hospital, physician, and patient enrollment populations; many relied heavily on grants rather than user fees, and SAIC determined they may not be self-sustaining over the life of the CDC contract.

Based on these findings SAIC created criteria for selecting an HIE team. These criteria included team members that would: be viable for the duration of the contract; have significant existing health care data exchange; include strong representation of state and local public health; have established external data sharing precedents to enable rapid implementation of the minimum biosurveillance data set (MBDS); and have experience in developing local public health tools. Table 1 provides a high-level description of the main roles and responsibilities of each NW-PHIE member. 
Table 1. NW-PHIE Roles and Responsibilities

\begin{tabular}{|l|l|}
\hline Organization & Role/Responsibility \\
\hline $\begin{array}{l}\text { Idaho Department of Health } \\
\text { \& Welfare (ID DOHW) }\end{array}$ & $\begin{array}{l}\text { Provide Idaho requirements for biosurveillance, case } \\
\text { reporting and public health alerting. Assist in getting } \\
\text { biosurveillance and case reporting information to ID } \\
\text { local public health. }\end{array}$ \\
\hline $\begin{array}{l}\text { Inland Northwest Health } \\
\text { Services (INHS) }\end{array}$ & $\begin{array}{l}\text { Serve as the main point of interface into clinical care } \\
\text { through its 34 hospitals, 3,500 beds, numerous } \\
\text { laboratories, two regional imaging centers, 400 } \\
\text { physicians offices, and 2.6 million longitudinal } \\
\text { electronic health records. }\end{array}$ \\
\hline $\begin{array}{l}\text { Science Applications } \\
\text { International Corporation }\end{array}$ & $\begin{array}{l}\text { Serve as prime contractor for the NW-PHIE team on the } \\
\text { CDC Situational Awareness contract. SAIC has } \\
\text { leveraged its extensive experience in connecting clinical } \\
\text { care to public health and developing disease surveillance } \\
\text { systems. }\end{array}$ \\
\hline $\begin{array}{l}\text { Spokane Regional Health } \\
\text { District (SRHD) }\end{array}$ & $\begin{array}{l}\text { Serve as a focal point for connecting public health with } \\
\text { Spokane practitioners. Participate in understanding how } \\
\text { the minimum biosurveillance data set (MBDS) can } \\
\text { assist local health departments and develop bi- } \\
\text { directional communications between public health and } \\
\text { clinical care practitioners. }\end{array}$ \\
\hline $\begin{array}{l}\text { Washington } \\
\text { Department of Health (WA } \\
\text { DOH) }\end{array}$ & $\begin{array}{l}\text { Assist state and local public health departments in using } \\
\text { the clinical data streams created by this contract to } \\
\text { improve public health practices and outcomes. }\end{array}$ \\
\hline $\begin{array}{l}\text { Informatics (UW CPHI) } \\
\text { created under this contract into existing DOH } \\
\text { surveillance systems. }\end{array}$ \\
\hline
\end{tabular}

Inland Northwest Health Services (INHS) is the HIE platform for NW-PHIE. INHS is a non-profit regional collaboration to improve patient care through innovative technology solutions and shared services. INHS has electronically linked 34 hospitals, with more than 3,500 beds, across Washington and Idaho. These facilities share a common information system featuring a unified Master Patient Index (MPI). Clinics outside the network receive data via standard electronic messages, and physicians can view the data via the internet or wirelessly in the hospitals. Laboratories and imaging centers contribute data to the integrated system. The same shared services approach has been used to develop a centralized electronic medical record service for physician offices, currently serving more than 700 physicians across the region. INHS also operates an extensive telehealth network, linking 68 hospitals, clinics and public health agencies around the region. This system is used to deliver health care and continuing education to rural patients and practitioners. The regional integrated information system and telehealth has allowed the implementation of a wide variety of technical innovations, including computerized physician order entry, nursing documentation, bar-coded medication 
verification systems, and tele-ER. INHS also provides other shared services, including a regional air ambulance service, community health education, and physical rehabilitation programs.

\section{Review of Accomplishments and Current Activities}

Project Outreach to Stakeholders: An important initial step was to educate the clinical community about the goals of the Situational Awareness project and gain their commitment to participate. INHS assembled a kickoff meeting for hospital administrators and health information managers from many of their 34 member hospitals with representatives of CDC, WA DOH and SRHD. This meeting allowed the hospital representatives to better understand project goals and benefits, as well as provided a forum for answering the hospital representative's questions. INHS staff also met multiple times with a regional coalition of health information managers to review the project and answer questions.

While hospitals in the region were accustomed to reporting notifiable conditions to public health agencies and have a long history of working cooperatively with public health, they were not familiar with the concept of syndromic surveillance and were hesitant about a project that required routine reporting of so much data on almost all of their patients. They were particularly uncomfortable with the requirement for pseudo-anonymization of patients and questioned whether or not their patients' privacy would truly be protected.

INHS worked with SRHD to help the hospitals understand how syndromic surveillance fits within the framework of the existing Washington state notifiable condition regulations. SRHD was also very effective at leveraging its relationship with hospital infection control staff to decrease concerns about the new project and to establish a patient re-identification process that would fit within the hospital's current processes and reassure the hospitals about their own ability to protect their patients' privacy. Based on this background work, data sharing agreements were signed with Sacred Heart Medical Center (SHMC), the largest hospital in the region. Once SHMC agreed to participate, other hospitals quickly agreed to sign data sharing agreements.

Collaboration with other HIEs and Public Health Agencies: An important aspect of our project is to promote the benefits to public health of collecting health information from health information exchanges. To support this we presented our work efforts at numerous healthcare, health informatics and public health conferences (see Table 2). These presentations helped us disseminate information on the methods and practices we employed in connecting HIEs to public health. 
Table 2. Presentations on the Benefits of Collecting Syndromic Surveillance Data from HIEs

\begin{tabular}{|c|c|c|}
\hline Meeting & Date & Objective \\
\hline $\begin{array}{l}\text { CDC HIE Community of } \\
\text { Practice }\end{array}$ & Feb 2009 & $\begin{array}{l}\text { Presentation of NW-PHIE project to the CDC's HIE } \\
\text { community of practice. }\end{array}$ \\
\hline $\begin{array}{ll}\begin{array}{l}\text { HIMSS } 2009 \\
\text { presentation }\end{array} & \text { HIE } \\
\end{array}$ & $\begin{array}{l}\text { April } \\
2009\end{array}$ & $\begin{array}{l}\text { Participation in joint CDC SA awardees' } \\
\text { presentation on our HIE project. }\end{array}$ \\
\hline 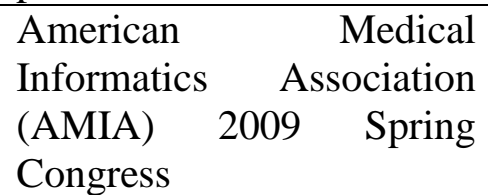 & May 2009 & $\begin{array}{l}\text { Participation in a panel discussion on HIEs and } \\
\text { public health.[4] }\end{array}$ \\
\hline $\begin{array}{lr}\text { Sharing } & \text { Summarized } \\
\text { Syndromic } & \text { Surveillance } \\
\text { Data Meeting in NYC }\end{array}$ & June 2009 & $\begin{array}{l}\text { Meeting with CDC, NY, NYC, IN and WA DOH at } \\
\text { the NYC Department of Health and Mental Hygiene } \\
\text { (DHMH) to discuss summarized syndromic } \\
\text { surveillance data. This meeting resulted in the } \\
\text { development of the Geocoded Interoperable } \\
\text { Population Summary Exchange (GIPSE) } \\
\text { specification. }\end{array}$ \\
\hline $\begin{array}{l}\text { Council of State and } \\
\text { Territorial Epidemiologist } \\
\text { (CSTE) } 2009 \text { Conference }\end{array}$ & June 2009 & $\begin{array}{l}\text { Participation in a presentation and question and } \\
\text { answer session on HIEs and public health.[5] }\end{array}$ \\
\hline $\begin{array}{l}\text { PHIN } 2009 \text { Conference } \\
\text { HIE presentation }\end{array}$ & Sept 2009 & $\begin{array}{l}\text { Participation in a joint CDC Situational Awareness } \\
\text { (SA) awardees' presentation on our HIE project } \\
\text { entitled "Public health and HIEs: Developing a } \\
\text { Common Roadmap to Success".[6] }\end{array}$ \\
\hline $\begin{array}{lr}\text { American } & \text { Medical } \\
\text { Informatics } & \text { Association } \\
(\text { AMIA) 2009 } & \text { Annual } \\
\text { Symposium } & \\
\end{array}$ & Nov 2009 & $\begin{array}{l}\text { Participation in a joint CDC SA awardees' } \\
\text { presentation on HIEs and public health. }\end{array}$ \\
\hline $\begin{array}{lr}\text { International } & \text { Society of } \\
\text { Disease } & \text { Surveillance } \\
\text { (ISDS) 2009 Annual } \\
\text { Conference }\end{array}$ & Dec 2009 & $\begin{array}{l}\text { Poster presentation comparing NW-PHIE's } \\
\text { influenza surveillance data to data provided through } \\
\text { WA DOH's influenza-like-illness Network (ILI } \\
\text { Net) providers. [7] }\end{array}$ \\
\hline CSTE 2010 Conference & June 2010 & $\begin{array}{l}\text { Participation in a presentation and question and } \\
\text { answer session on HIEs and public health.[8] }\end{array}$ \\
\hline $\begin{array}{l}\text { National Association of } \\
\text { City and County Health } \\
\text { Officials (NACCHO) }\end{array}$ & July 2010 & $\begin{array}{l}\text { Demonstration of how our project helped state and } \\
\text { local public health organizations. }\end{array}$ \\
\hline
\end{tabular}

In addition to presenting at conferences we also demonstrated current and leading edge technologies that we are using (or hope to use) as part of our technical infrastructure for connecting HIEs to public health. The goal is to reinforce with the healthcare and public health communities that the technologies for connecting HIEs to public health already 
exist and to demonstrate how those technologies work. Table 3 lists the technology demonstrations in which we have participated.

Table 3. NW-PHIE's Technology Demonstrations

\begin{tabular}{|l|l|l|}
\hline Meeting & Date & Objective \\
\hline $\begin{array}{l}\text { NHIN Gateway } \\
\text { Washington, D.C. }\end{array}$ & Dec 2008 & $\begin{array}{l}\text { Demonstrate how NHIN Gateway can support the } \\
\text { sharing of information between HIEs and public } \\
\text { health. }\end{array}$ \\
\hline $\begin{array}{l}\text { HIMSS } 2009 \\
\text { Connectathon Testing }\end{array}$ & Feb 2009 & $\begin{array}{l}\text { Test interoperability capabilities with EHR } \\
\text { vendors in preparation for the 2009 HIMSS } \\
\text { Interoperability Showcase. }\end{array}$ \\
\hline $\begin{array}{l}\text { HIMSS } \\
\text { Conference } \\
\text { Interoperability }\end{array}$ & $\begin{array}{l}\text { April } \\
\text { Showcase }\end{array}$ & $\begin{array}{l}\text { Demonstrate how the NHIN Gateway can be used } \\
\text { to send syndromic surveillance data encoded using } \\
\text { the HITSP biosurveillance format to the CDC. } \\
\text { Also demonstrated EHR public health alerting } \\
\text { using Integrating the Healthcare (IHE) and Health } \\
\text { Information Technology Standards Panel(HITSP) } \\
\text { profiles. }\end{array}$ \\
\hline $\begin{array}{l}\text { PHIN } \\
\text { Conference } \\
\text { Snteroperability }\end{array}$ & Sept 2009 & $\begin{array}{l}\text { Two PHIN Interoperability Showcase scenarios: } \\
\text { (1) EMR public health alerting and (2) influenza } \\
\text { surveillance using summarized counts (GIPSE) } \\
\text { and the NHIN gateway. }\end{array}$ \\
\hline $\begin{array}{l}\text { Capital Hill Health } \\
\text { Information } \\
\text { Technology Week }\end{array}$ & Sept 2009 & $\begin{array}{l}\text { Demonstrate a biosurveillance scenario using } \\
\text { GIPSE and the NHIN Gateway to Congressional } \\
\text { members and staff. }\end{array}$ \\
\hline $\begin{array}{l}\text { IHE Connectathon } \\
\text { Testing }\end{array}$ & Jan 2010 & $\begin{array}{l}\text { Test interoperability capabilities with EHR } \\
\text { vendors in preparation for the 2010 HIMSS } \\
\text { Interoperability Showcase. }\end{array}$ \\
\hline $\begin{array}{l}\text { HIMSS } \\
\text { Shteroperability }\end{array}$ & $\begin{array}{l}\text { Participate in demonstration scenarios that showed } \\
\text { how HIEs and public health can communicate to } \\
\text { identify and manage disease outbreaks using } \\
\text { decision support tools and web-based public health } \\
\text { alerting systems. }\end{array}$ \\
\hline
\end{tabular}

Capturing Relevant Clinical Data: SAIC took the lead in developing the technical solution for collecting biosurveillance data and sending it to public health. SAIC's solution, called the Biosurveillance Integrator, works by filtering clinical information to find relevant biosurveillance data, removes personally identifiable information, creates standardized biosurveillance messages and sends them to the WA DOH, SRHD and eventually on to the $\mathrm{CDC}$. The Biosurveillance Integrator takes as input clinical information (HL7 messages, EHR export files, etc.) and filters those data based on the rules specified in the American Health Information Community (AHIC) biosurveillance use case. The biosurveillance messages that are created conform to the HITSP biosurveillance message standards. INHS configured their Cloverleaf integration engine to send existing HL7 messages to SAIC's Biosurveillance Integrator and also created 
custom file extracts from their resource utilization system and emergency department system.

The team installed, configured and tested the Public Health Information Network Messaging System (PHINMS) to securely send the biosurveillance files from INHS to WA DOH. PHINMS compresses, encrypts and digitally signs files before transporting them over the internet to WA DOH.

Within six months from project inception the project team was testing the Biosurveillance Integrator. In December 2008, nine months after project inception, NW-PHIE went live with the SHMC, the $2^{\text {nd }}$ largest hospital in WA State, sending biosurveillance messages to public health based on Admission/Discharge/Transfer (ADT) messages. In January 2009, the transmission of data for SHMC was expanded to cover laboratory orders and results. Approximately nine thousand ADT-based and seven hundred fifty order and result biosurveillance messages were being sent to public health daily based on the SHMC implementation.

In the next year of the project NW-PHIE implemented real-time syndromic surveillance data feeds to public health for thirteen additional hospitals. These hospitals are sending a detailed set of biosurveillance information including:

- Facility-level census and resource utilization information

- Patient-level

- Demographic information

- Emergency department chief complaint, working and final diagnosis

- Inpatient admission reason and final diagnosis

o Outpatient reason for visit and final diagnosis

Most of the NW-PHIE's efforts have been focused on analyzing the patient-level data.

INHS hospitals had text-based laboratory results that are hard to programmatically analyze. In order to better analyze the laboratory data the NW-PHIE implemented eleven discrete hospital laboratories interfaces. These discrete laboratory interfaces not only provide better syndromic surveillance data, they also provide a foundation for performing reporting on laboratory results for notifiable disease conditions. To further improve the ability to analyze laboratory test orders and results we mapped local laboratory test code to Logical Observation Identifiers Names and Codes (LOINC®) laboratory test codes and local test results (e.g., organisms, result codes) to codes from the Systemized Nomenclature of Medicine-Clinical Terms (SNOMED CT®).

NW-PHIE's Population Coverage: The map in Figure 1 shows NW-PHIE's patient catchment area in Washington, Oregon, Idaho and Montana. Based on the patient's zip code, the map depicts the number of patient encounters per capita NW-PHIE filtered from November 6, 2009 through February 5, 2010 (3 months). Darker colors indicate that a higher per capita number of patient encounters were filtered from that zip code. Prior to the initiation of our project there was no automated filtering of patient encounters for public health situational awareness in these catchment areas. 


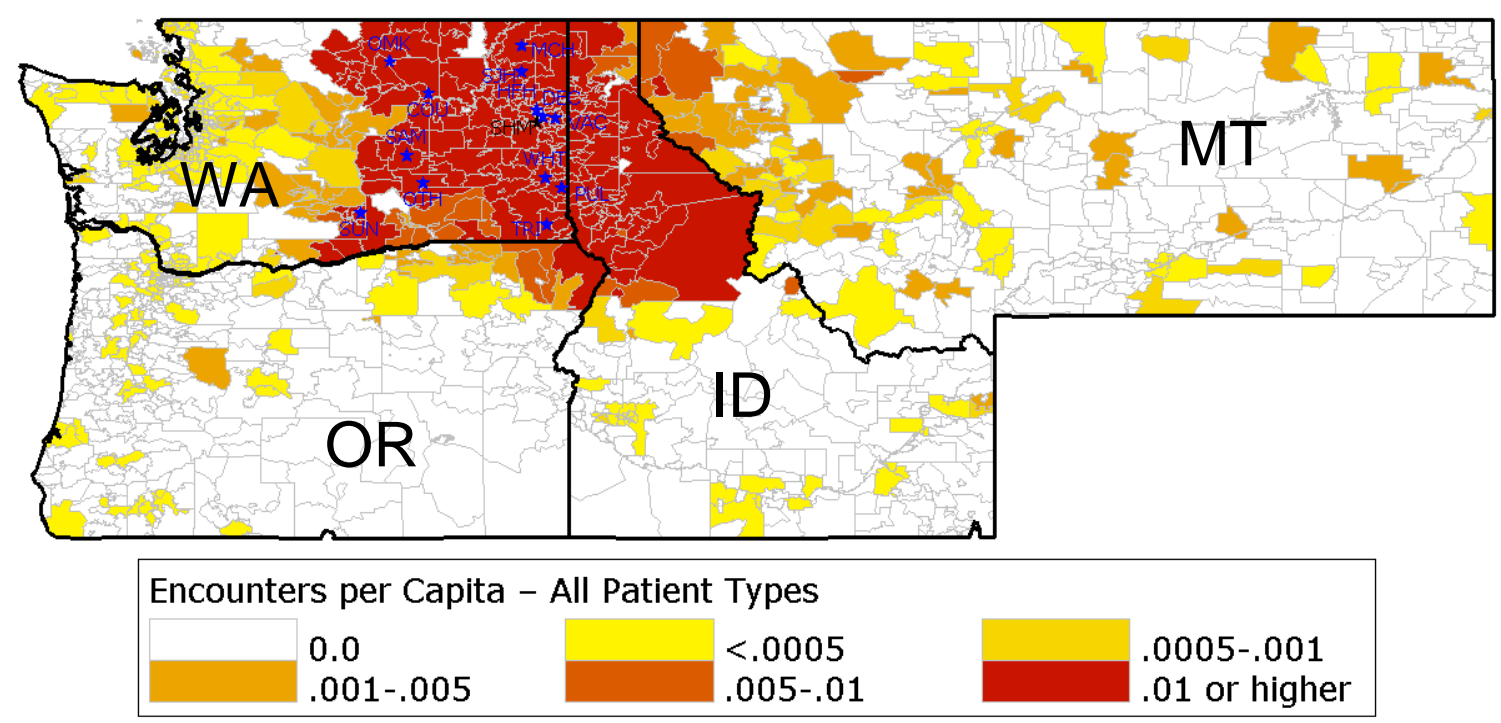

Figure 1. NW-PHIE's Per Capita Patient Encounters for the 4th Quarter of 2009 (based on the Patient's zip code)

Throughout the life of the project we have steadily increased the number of patient encounters filtered as can be seen in Figure 2.

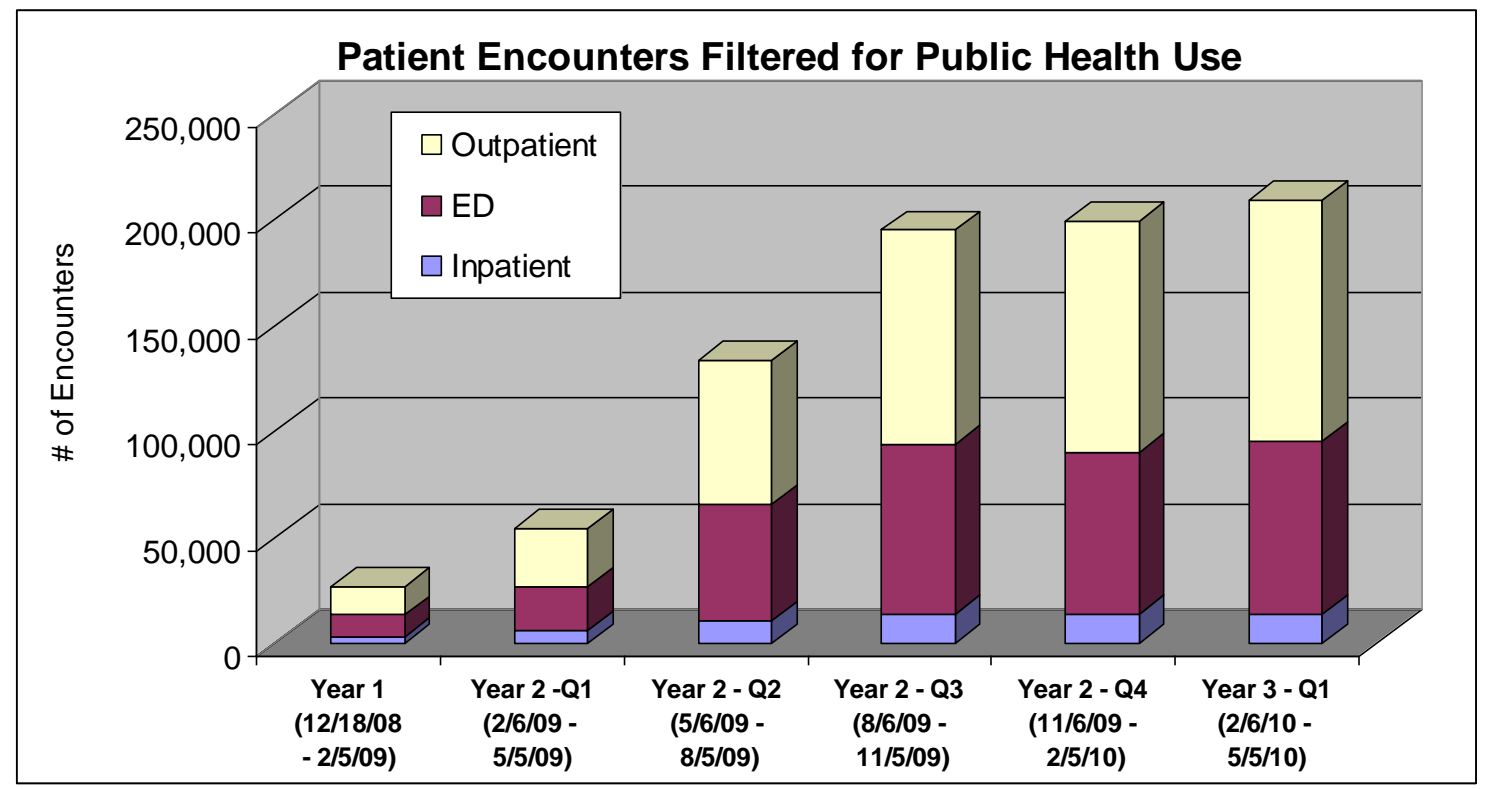

Figure 2. Number of Patient Encounters Filtered by Project Quarter

Analyzing Biosurveillance Data for Public Health Purposes: The biosurveillance information being sent to public health is patient-level, transactional data. UW developed a process for taking the transactional data and creating a patient encounter record which then gets analyzed to identify incidents of importance to public health. 
In the spring of 2009 the H1N1 pandemic occurred. This was a galvanizing event for public health resulting in a full-court press on gathering information to characterize H1N1 outbreak and help manage the response. NW-PHIE, in concert with epidemiologist and informaticists from CDC, NY and IN, quickly developed algorithm specifications for filtering clinical encounter information to identify cases of influenza, influenza-likeillness, and pneumonia as well as a file format to convey the indicator counts. These filter algorithms are called indicators and can be based on:

- Words or phrases in chief complaints, nurse triage notes or admission reasons

- ICD-9 diagnosis codes

- Test/procedure codes

- Test order or result codes

In order to compare rates we developed both numerator and denominator indicators. Numerator indicators identify the number of patients with a given condition and denominator indicators provide a total count of the population of patients surveyed.

Because of the variability of patient-level data captured by different organizations it was important to define numerous indicators that cover the breath of possible data captured. Over forty different numerator indicator specifications for influenza, ILI, and pneumonia were developed and four different denominator definitions.

The file format for conveying the indicator counts is called the Geocoded Interoperable Population Summary Exchangefile and is designed to allow the electronic exchange of health indicator counts that can be stratified by a number of variables, including age group, gender, patient class, discharge disposition and geography (zip) [9].

On September 1, 2010 NW-PHIE began sending a GIPSE file of 10 different influenza indicators to the WA DOH, SRHD and CDC. This file has a rolling 30 days of GIPSE indicators stratified by three digit zip, gender, eight age ranges, patient class and a UB40based discharge disposition. These data can easily be imported to create epidemiology curves such as the one depicted in Figure 3.

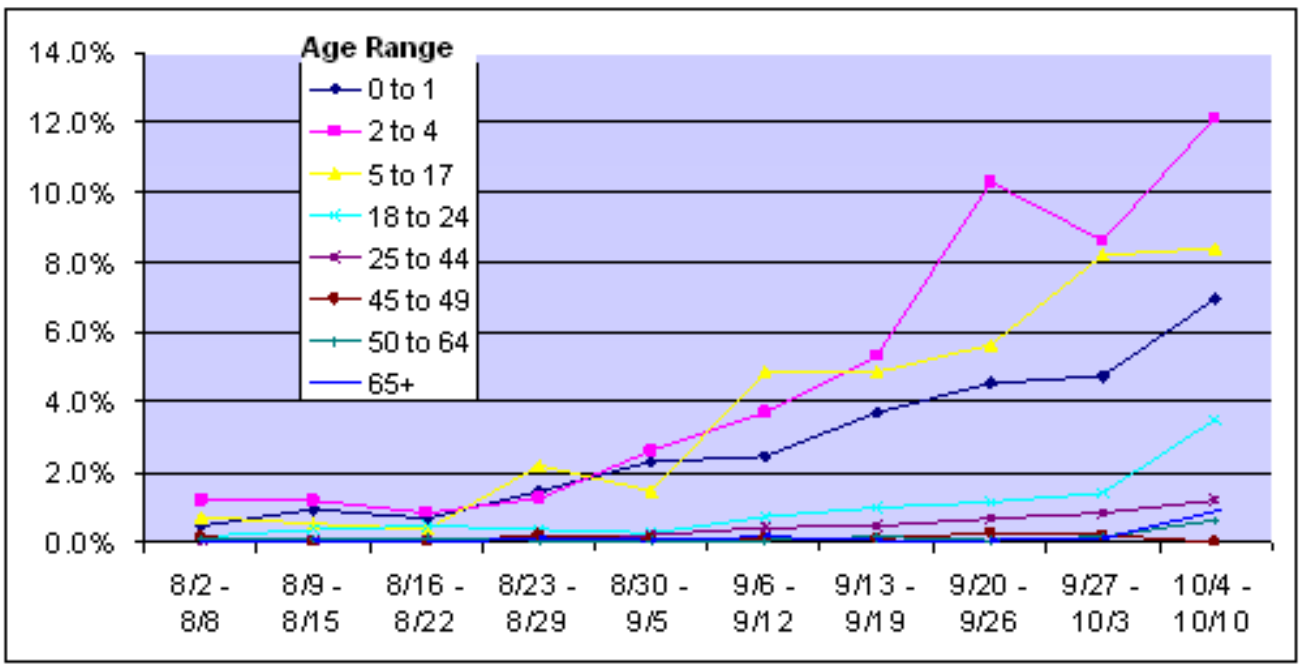

Figure 3. Rate of Influenza-Like-Illness Chief Complaints for ED Patients by Age Group based on NW-PHIE GIPSE File from October 2009 
While these data were useful to epidemiologists in understanding the size of the influenza outbreak they did not answer questions about possible changes in the severity of illness over time and the rate of influenza vaccinations and the vaccine's effectiveness. To help answer these questions NW-PHIE met with emergency department personnel and developed a means to capture a patient's temperature and blood oxygen saturation to help characterize severity of illness, and a patient's self reported seasonal and H1N1 vaccination status to help characterize vaccination rates and effectiveness.

To cover these additional data elements NW-PHIE began sending four additional indicators:

- Hypoxemia - initial pulse oximetry reading saturation $<95 \%$

- Fever - measured temperature $\geq 100$

- Self-Reported Seasonal Influenza Vaccination

- Self-Reported Influenza A/H1N1 vaccination

We also combined these four new indicators with several of our existing influenza indicators to create twelve new composite indicators, as seen in Table 4.

Table 4. Composite Indicators for Severity and Vaccination Status

\begin{tabular}{|c|c|c|c|c|}
\hline Influenza Indicator & Hypoxemia & Fever & $\begin{array}{l}\text { Self Repo } \\
\text { Seasonal } \\
\text { Influenza }\end{array}$ & Vaccination \\
\hline $\begin{array}{l}\text { Influenza-like-illness } \\
\text { chief complaint }\end{array}$ & $\checkmark$ & $\checkmark$ & $\checkmark$ & $\checkmark$ \\
\hline $\begin{array}{l}\text { Influenza-like-illness } \\
\text { diagnosis }\end{array}$ & $\checkmark$ & $\checkmark$ & $\checkmark$ & $\checkmark$ \\
\hline Influenza diagnosis & $\checkmark$ & $\checkmark$ & $\checkmark$ & $\checkmark$ \\
\hline
\end{tabular}

These additional indicators have proven extremely helpful in more fully characterizing the H1N1 outbreak.

Comparing GIPSE Influenza Indicators to ILINet Counts: WA DOH undertook a study to compare the utility of NW-PHIE's influenza surveillance indicators to those of the existing influenza-like-illness Network (ILINet) data from WA sentinel providers. The comparison metrics include representativeness, stability and timeliness of the data. Figure 4 plots the percent of patient encounters indicating ILI (rate of ILI) from both the ILINet sentinel providers and from NW-PHIE emergency department and outpatient encounters. These rates are overlaid on a plot of the number of laboratory confirmed cases reported to WA DOH during the same week. The chart shows that NW-PHIE's ILI rates are more stable over time and align more closely with the trend of laboratory confirmed cases than ILINet's. 


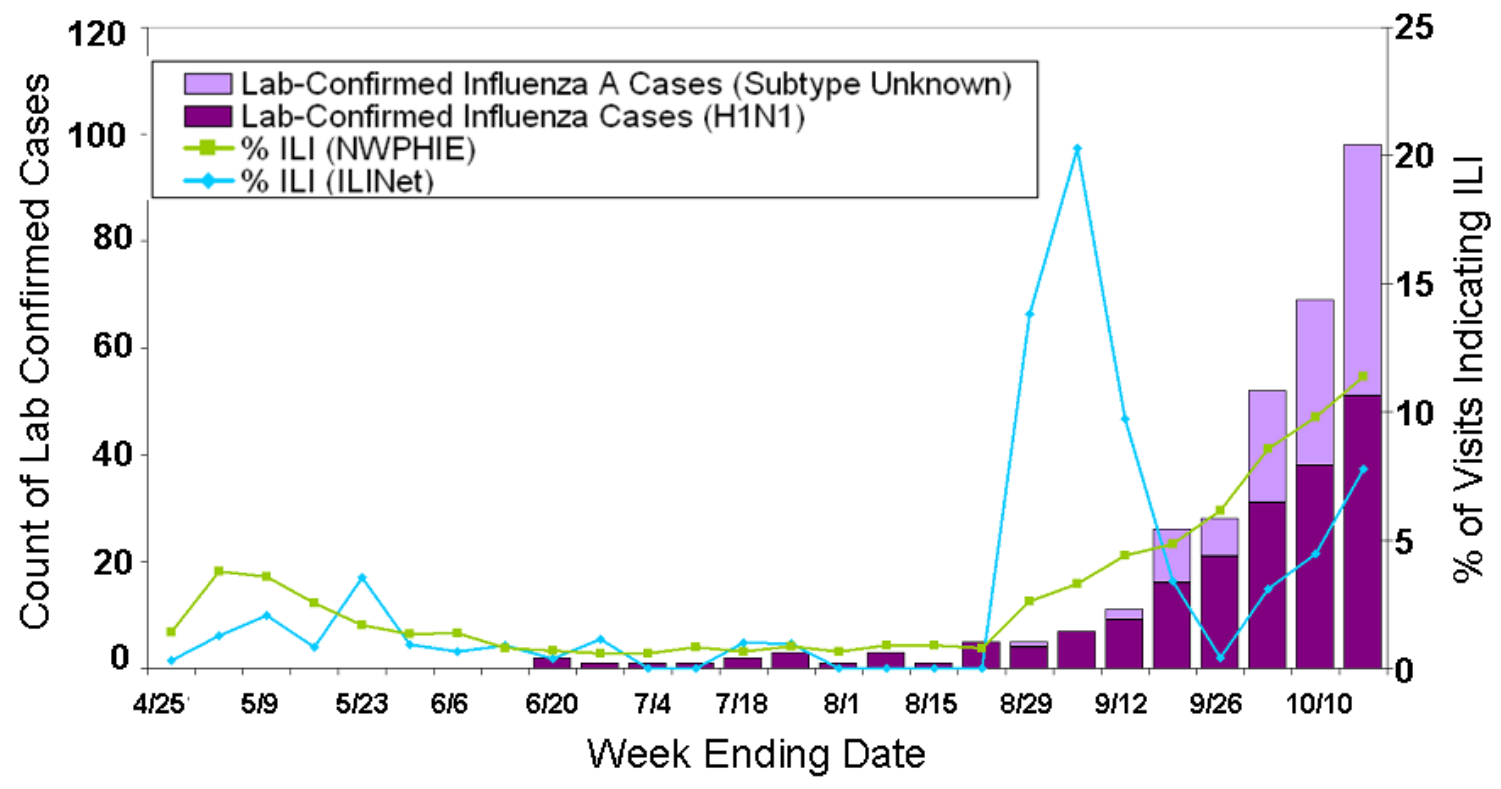

Figure 4. ILI Rate from NW-PHIE and ILINet overlaid with Laboratory Confirmed Influenza Cases

In analyzing the stability of the ILI data feeds WA DOH found that NW-PHIE data are resistant to the seasonal fluctuations seen in reporting among ILINet reporters and, because of the large number of visits monitored by NW-PHIE, the data are not significantly affected by events at a single site. NW-PHIE ILI data were more timely with a consistent one day delay in reporting to WA DOH (i.e., the prior day's results are reported the following morning to WA $\mathrm{DOH}$ ) versus a median of 11.8 days delay for ILINet reporting to the WA DOH. NW-PHIE's ten day improvement in reporting timeliness can be essential in helping public health respond to an outbreak.

Current Activities: The final major effort of NW-PHIE is to implement automated reporting to public health of laboratory notifiable findings from INHS hospital laboratories. In public health's parlance this capability is referred to as electronic laboratory reporting (ELR). ELR is a complex undertaking. WA State law identifies seventy-seven disease conditions that are notifiable to public health and each county may have additional disease conditions that require notification to public health.

SAIC is developing and implementing an ELR solution that builds on the standardization of the laboratory results messages that occurred as part of the biosurveillance data feeds to public health. Additional efforts required to implement a full the ELR solution include:

- Expanding the laboratory result messages analyzed past the microbiology-based results that are analyzed for biosurveillance. These lab results need to have their test and results codes mapped to LOINC and SNOMED codes, respectively.

- Developing a knowledgebase that stores the rules for filtering laboratory results to identify notifiable disease conditions. 
- Creating and maintaining an encounter summary database that contains patient demographic, visit and physician information required on an ELR report but not available in a laboratory result messages.

- Creating standardized ELR messages to public health that are encoded using standardized vocabulary.

Of particular importance is the development of a knowledgebase that stores the rules for filtering public health results. The knowledgebase SAIC has developed stores the relationship of notifiable conditions to LOINC laboratory test codes. For each laboratory test that can be used to identify a notifiable disease condition the knowledgebase stores the possible result types (text, coded entry, numeric, structured numeric) and result values that indicate the presence of the notifiable disease condition.

In developing this knowledgebase SAIC made use of the Council of State and Territorial Epidemiologists' (CSTE) Technical Implementation Guides (TIG) for notifiable disease conditions, the Notifiable Disease Condition Mapping Tables (NCMT) published by CDC and the Regenstrief LOINC Mapping Assistance (RELMA). The SAIC developed ELR filtering rules knowledgebase has several thousand entries.

SAIC and INHS plans call for implementing ELR for an initial hospital in the fall of 2010 and with an additional implementation by the end of 2010 .

\section{Conclusion}

NW-PHIE has greatly improved public health's ability to monitor and respond to health emergencies in central and eastern WA. Prior to the initiation of NW-PHIE's Situational Awareness project no syndromic surveillance data feeds were being sent to public health from hospitals in central and eastern WA. Within the first two years of the project NWPHIE has implemented fourteen hospitals, representing close to a million patient encounters a year, that are sending a full set of syndromic surveillance data to public health. Two additional hospitals will begin sending syndromic surveillance data feeds to pubic health in the fall of 2010. These syndromic surveillance data feeds have proven vitally important in helping manage the recent $\mathrm{H} 1 \mathrm{~N} 1$ outbreak and are available to help manage future outbreaks whether from ILI or other types of disease.

SAIC has designed and developed an automated process for performing ELR for WA State's seventy-seven notifiable disease conditions. To support the ELR process NWPHIE has implemented eleven discrete hospital laboratory feeds. SAIC's ELR solution is being implemented for an initial hospital laboratory in the fall of 2010 with another hospital laboratory implementation planned by year end 2010 .

In addition to making a difference in improving the sharing of clinical information among clinical care and public health NW-PHIE's Situational Awareness project has advanced the National agenda for sharing interoperable health information with public health. NWPHIE has implemented HITSP Biosurveillance standards, developed a specification for 
sharing summary syndromic surveillance data and demonstrated how the NHIN Gateway and services can be used to support public health surveillance. Our project, along with those from IN and NY, has provided a roadmap for how public health can participate and derive value from HHS funded state HIEs. Our efforts should also help clinical care understand ways in which they can achieve the public health reporting requirements of EHR meaningful use.

\section{References}

[1] Cohn SP and National Committee on Vital and Health Statistics. Report to the Secretary of the U.S. Department of Health and Human Services on Functional Requirements Needed for the Initial Definition of a Nationwide Health Information Network (NHIN). 10/31/2006. http://www.ncvhs.hhs.gov/061030lt.pdf

[2] Rishel W, Riehl V, Blanton C. Summary of the NHIN Prototype Architecture Contracts. A Report for the Office of the National Coordinator for Health IT. 05/31/2007. http://healthit.hhs.gov/portal/server.pt/gateway/PTARGS_0_10731_848093_0_0_18/sum mary_report_on_nhin_Prototype_architectures.pdf

[3] Sutherland J. Regional Health Information Organization (RHIO): Opportunities and Risks. V 2.1. 11/2005.

http://www.himss.org/Content/Files/Sutherland_RHIO_WhitePaper.pdf

[4] Safran C, Garrett N, Dente M, Le L, Grannis S, Karras B. Panel: Translating Public Health Information into Clinical Action: A National Demonstration Project / Connecting Public Health to Clinical Care through Health Information Exchange - Implementation of AHIC Biosurveillance. AMIA Spring Congress, May 2009. Available at http://2009springcongress.amia.org/files/congress2009/AMIA_Spring_Congress_On-

Site_Program.pdf

[5] Magruder C, Johnson G, Grannis S, Karras B. Enhancing Public Health Practice Through Health Information Exchange - New York, Indiana, and Washington/Idaho Perspectives. 2009 CSTE Annual Conference, June 2009. Available at http://www.cste.org/dnn/AnnualConference/2009AnnualConferenceArchive/tabid/321/D efault.aspx

[6] Magruder C, Dobbs D, Karras B, Blake PA, Grannis S, Johnson GS. Public Health and Health Information Exchanges: Developing a Common Roadmap to Future Success. 2009 PHIN Annual Conference, 2009. Available at

http://cdc.confex.com/cdc/phin2009/webprogram/Paper21174.html

[7] Close N, Lofy K, Sandifer T, Lowe P, Karras BT. Utilization of Washington State's Public Health Emerging Event Detection System (PHEEDS) for 2009 H1N1 Surveillance. ISDS Meeting, 2009.

[8] Karras B, Gibson J, Johnson G. Public health and health information exchange: Lessons learned - a Centers for Disease Control and Prevention sponsored initiative in New York, Indiana and Washington/Idaho. 2010 CSTE Annual Conference, June 2010. Available at http://cdc.confex.com/cdc/phin2009/webprogram/Paper21174.html

[9] HIEM/Profile Development Work Group. Geocoded Interoperable Population Summary Exchange (GIPSE). Profile Definitio. V 1.0. 09/03/2009. Available at http://healthit.hhs.gov/portal/server.pt/gateway/PTARGS_0_10741_909195_0_0_18/GIP $\underline{\text { SEProfileSpecification.pdf }}$ 


\section{Acknowledgments}

This work was funded by the Centers for Disease Control and Prevention through the "Accelerating Public Health Situational Awareness through Health Information Exchanges" contract \#200-2008-24369 and was made possible by the efforts of the entire NW-PHIE Collaborative.

\section{Correspondence}

David Dobbs, Science Applications International Corporation, McLean, VA. dobbsd@saic.com

\section{Conflicts of Interest}

The authors do not report any conflicts of interest. 